\title{
A Study on Parents' Willingness to Pay for Online Learning of Middle School Students Based on Perceived Value
}

\author{
Guomin Chen, ${ }^{1}$ Xiaoyong Zhou, ${ }^{1}$ Yingwei Jin, ${ }^{2}$ and Yang Liu ${ }^{3}{ }^{3}$ \\ ${ }^{1}$ School of Management, Guilin University of Aerospace Technology, Guilin, China \\ ${ }^{2}$ Dalian University of Technology, Dalian, China \\ ${ }^{3}$ Jilin Business and Technology College, Changchun, China \\ Correspondence should be addressed to Yang Liu; 2020152@guat.edu.cn
}

Received 22 October 2021; Accepted 16 November 2021; Published 18 December 2021

Academic Editor: Sang-Bing Tsai

Copyright (c) 2021 Guomin Chen et al. This is an open access article distributed under the Creative Commons Attribution License, which permits unrestricted use, distribution, and reproduction in any medium, provided the original work is properly cited.

The purpose of this study is to conduct a mixed research from the perspective of customers perceived value and objective situational factors. The online learning platform for middle school students has a special situation of users (students) using and customers (parents) paying. When it studies the influencing factors of customers (parents) willingness to pay, it puts aside the interference of users' using influencing factors and conducts a separate study. Firstly, the exploratory research based on the grounded theory carries out category extraction and model construction. Secondly, through empirical research to identify the specific relationship between the variables, we finally get the specific influencing factors of perceived value that affect customers' willingness to pay. In objective situations, social influence directly affects customers' willingness to pay. Online comments play a positive moderating role in the impact of perceived value on willingness to pay.

\section{Introduction}

In recent years, many countries have made a lot of development and investment in digital learning technology and online learning platform [1]. From traditional classroom teaching to online learning, great changes have taken place in all aspects of education [2,3]. With the vigorous development of online education, research perspectives are also diversified. Some scholars study on college students and teachers $[4,5]$. Some scholars focus on the adoption stage and continuous use stage of online learning platform [6, 7]. Some scholars mainly study open online course MOOCs [8-11]. In general, the research on the willingness to pay for online education of middle school students is still in the blank stage. This paper will study the willingness to pay for online learning platform of middle school students' parents.

This study focuses on the willingness of middle school students' parents to pay for online learning platform. Most of the middle school students are between 12 and 18 years old and have a certain subjective awareness of learning. Most of the middle school students' expenses mainly come from their parents. Understanding the parents' willingness to pay for students' online learning plays a vital role in the sustainable development of online learning platform.

\section{Research Design}

At present, there are few studies on the parents' willingness to pay for online learning of middle school students, even fewer references. It is difficult to determine the factors that influence the parents' willingness to pay, so the grounded theory research is firstly conducted to clarify the influencing factors. Secondly, the relationship between variables is explored through quantitative research. Thus, mixed research method is used in the design.

2.1. Research Process (Grounded Theory). There are few studies on parents' willingness to pay for online learning of middle school students. In order to better explore the theoretical mechanism, this paper uses the grounded theory method to analyze the text in the exploratory research stage 
and strives to summarize, analyze, and improve the relevant payment mechanism in the original text data. The sampling of grounded theory is theoretical sampling; that is, in order to propose a specific concept or construct a theory, we make a purposeful sampling selection. The selected samples must be closely related to the research topic and have sufficient representativeness [12]. Therefore, the research objects of this paper are composed of students' parents who have used online learning platforms. In order to ensure the comprehensiveness of the experimental results, in the study, parents of junior high school students and parents of high school students were selected as interview subjects. The basic situation of the respondents is shown in Table 1. Due to the epidemic situation, semistructured interviews were conducted through the Tencent Video Conference platform for four days (December 20, 2020-December 23, 2020). Five respondents were interviewed online every day, and each interview lasted for an average of 30 minutes. In return, each interviewee can obtain one month of free online learning opportunity for their child (January 21, 2021-February 20, 2021). The interview questions are mainly about the parents' choice of online learning platform, the reasons of platform selection, the courses purchased, the influencing factors of curriculum selection, the information concerned, the purchase concerns, and the willingness to pay. Under the authorization of parents, the interviewer backups and records the interview content, and on this basis, the text is formed and analyzed theoretically. The whole process consists of open coding, principal axis coding, selective coding, and conceptual model.

2.2. Category Extraction and Model Construction. The first step to extract the influencing factors of middle school students' parents' willingness to pay for online learning is open coding. In the process of open coding, the original text is encoded sentence by sentence, and the scattered and specific concepts are transformed into abstract and theoretical concepts. The repeated and irrelevant information is deleted, and finally 65 initial categories are formed, as shown in Table 2 (see Table 3 for details).

The second step is principal axis coding. The purpose of principal axis coding is to further analyze the initial category on the basis of open coding, form the main category and the subcategory, and discover the potential logic and generic relationship between categories. Through exploratory analysis of logical relations, 33 subcategories and 11 main categories are finally formed. Among them, teaching information, teachers and students' information, perceived risk, perceived cost, recommendations from people around, external publicity, help to improve learning, help to improve ability, perceived value, online comments, and willingness to pay are 11 main categories, detailed in Table 4 (see Table 5 for details).

The third step is selective coding, which reintegrates the "core class" and further integrates the content of principal axis coding after systematic analysis of the discovered concept classes. The teaching information and teachers' and students' information are reclassified as course information,
TABLE 1: Basic information of respondents.

\begin{tabular}{lcc}
\hline Basic items & Classification & Number of samples \\
\hline \multirow{2}{*}{ Gender } & Male & 8 \\
& Female & 12 \\
\hline \multirow{2}{*}{ Children's grade } & Junior middle school & 13 \\
& High school & 7 \\
\hline \multirow{3}{*}{ Income level } & Below 2000 & 1 \\
& $2000-3500$ & 6 \\
& $3500-5000$ & 4 \\
& $5000-6500$ & 4 \\
& $6500-8000$ & 2 \\
& Over 8000 & 3 \\
\hline
\end{tabular}

and the surrounding people's recommendation and external publicity are classified as social influence. Help to improve learning and help to improve ability are classified as perceived usefulness. After the integration of 11 main categories, 8 concepts are finally formed, as detailed in Table 6 . By mining the relationship between categories to build the relationship between concepts, we can build a theoretical framework. For example, curriculum information affects perceived usefulness and perceived value, perceived usefulness, perceived risk and perceived cost affect perceived value, social influence and perceived value affect willingness to pay, and online comments moderate the relationship between perceived value and willingness to pay, as shown in Figure 1.

\section{Variable Interpretation and Hypothesis}

3.1. Course Information (CI). At present, there is no research on the definition of course information directly, so this paper draws on the relevant description of product information to analogy course information. Information plays a dual role both as a provider and a recommender for users. Information can be used either as a provider to provide products or services to users or as a recommender to help users make decisions [13]. For online shopping, rich objective product information helps buyers make decisions. Zhou et al. believe that if online retailers can provide comprehensive, timely, and persuasive information on products or services on Weibo, online retailers' brand equity and consumers' purchase intention will be enhanced [14]. For the construction of online learning platform, course information for students and parents is an important way to shape customer perceived value. Based on the above research results, this paper puts forward the hypothesis:

Hypothesis1: course information has a positive impact on perceived usefulness of middle school students' parents in online learning platform.

Hypothesis 2: course information has a positive impact on the perceived value of middle school students' parents in online learning platform.

3.2. Perceived Usefulness (PU). According to the definition of perceived usefulness by Zhou et al. [14], this study defines perceived usefulness as the degree to which the curriculum 
TABle 2: Open coding (part).

\begin{tabular}{|c|c|}
\hline Open coding & Original statement \\
\hline B1 course flow arran & Focus on the learning process of some courses \\
\hline $\begin{array}{l}\text { B2 fragmentation of course } \\
\text { time }\end{array}$ & $\begin{array}{c}\text { It's better if the course is a fragment chemistry seminar. Twenty minutes a day is more suitable for my } \\
\text { children }\end{array}$ \\
\hline B3 teaching time & $\begin{array}{l}\text { When I buy online classes for my children, I will pay attention to the class time which cannot conflict with } \\
\text { school or extracurricular classes }\end{array}$ \\
\hline $\begin{array}{l}\text { B4 sequence of content } \\
\text { arrangement }\end{array}$ & Learn about the order in which knowledge can be learned through online courses \\
\hline $\begin{array}{l}\text { B5 the difficulty of course } \\
\text { content }\end{array}$ & The difficulty of the course, the key and difficult points of the curriculum is my main concern \\
\hline content is clear & The introduction of online cou \\
\hline B7 s & First look at the \\
\hline B8 course content system & I will buy systematic classes for my children, including preview class, basic clas \\
\hline B9 course suppor & $\begin{array}{c}\text { Before purchasing the course, I will check the supporting services related to the course, such as whether } \\
\text { there are supporting exercise solutions }\end{array}$ \\
\hline B10 teacher's e & Focus on previous experience of the course instructor \\
\hline
\end{tabular}

TABle 3: Open coding.

Open coding

B1 course flow arrangement

B2 fragmentation of course time

B3 teaching time

B4 sequence of content arrangement

B5 the difficulty of course content

B6 the content is clear

B7 syllabus

B8 course content system

B9 course supporting services

B10 teacher's experience

B11 teaching methods

B12 teacher qualification

B13 teacher style

B14 teacher's detailed introduction

B15 teachers' moral character

B16 excellent students

B17 waste of time

B18 care for children's eyes

B19 children do not like it

B20 the learning effect is not good

B21 poor learning outcomes

B22 system delete

B23 waste of money

B24 focus on cost performance

B25 the price is within the acceptable range

B26 beyond affordability

B27 courses need to be paid

B28 high price
Original statement

Focus on the learning process of some courses

It's better if the course is a fragment chemistry seminar. Twenty minutes a day is more suitable for my children

When I buy online classes for my children, I will pay attention to the class time which cannot conflict with school or extracurricular classes

Learn about the order in which knowledge can be learned through online courses

The difficulty of the course, the key and difficult points of the curriculum is my main concern The introduction of online course content must be reasonable and clear

First look at the teaching box of the catalog

I will buy systematic classes for my children, including preview class, basic class, intensive class, etc

Before purchasing the course, I will check the supporting services related to the course, such as whether there are supporting exercise solutions

Focus on previous experience of the course instructor

Before purchasing, I will consider whether it is a live class or a video class

Before buying courses for children, I will pay attention to the qualifications of teachers

The final purchase of courses for children is mainly influenced by the teacher. Consider whether the teacher's teaching style and teaching method can be accepted by children

Buying lessons for children, I mainly focus on the teacher's detailed introduction and then decide

When I choose courses for my children, I also pay attention to the teacher's conduct

I mainly focus on the examination results of the students in the online mathematics class, which

shows whether the students are good at learning and the teachers are good at teaching

I am afraid that the course is not good, it not only costs money but also wastes children's time Curriculum design should be reasonable to protect children's eyes

I'm worried that children do not like this course and cannot learn anything after buying it

I'm worried about the children's understanding, acceptance and help of the course

I'm worried that after finishing the final exam, my child's grades are still not good

I'm afraid that after I pay the money, their system will delete me. The money will be wasted and the children will not be able to attend class

The main fear is that children's learning will be ineffective and the money will be wasted Generally, when I buy, I will also consider the cost performance ratio. If the price is not particularly high, I will not have any worries. If the price is very high, I will depend on the demand of children

If the price is particularly high, I will not consider it. On the premise of ensuring the quality of teaching for children, I will also be within my own range

If the course is too expensive, I cannot afford a training class

Although there are some free courses on some platforms, many courses child needs are paid for. The online class fees I reported for my children are very high 
TABLE 3: Continued.

Open coding
B29 charging interval
B30 teacher's recommendation
B31 recommended by parents
communication group
B32 recommended by parents

B33 parents' meeting consultation

B34 recommended by friends

B35 network media publicity

B36 cope with exams

B37 achieve the goal

B38 improve the level of Chinese

B39 focus on teaching

B40 the needs of the curriculum

B41 the content meets the needs of children

B42 emergency learning

B43 practical course

B44 improve children's ability

B45 improve mathematical thinking

B46 beyond expectations

B47 obvious progress

B48 the effect is remarkable

B49 learn the key methods

B50 targeted learning

B51 explanation of regional examination questions

B52 platform major and main courses

B53 the course arrangement is reasonable

B54 building learning group

B55 mock examination

B56 intelligent question bank

B57 course playback does not expire

B58 Weibo Q \& A

B59 comments on teaching content

B60 impact assessment

B61 teacher evaluation

B62 celebrity effect
Original statement

I will pay attention to the number of one-time paid courses, whether it is paid once every three months or half a year.

I Will choose the platform recommended by the teacher.

Parents exchange group will say whose class is good, I will go to pay attention to those teachers.

That teacher is very famous in beijing. Many parents say that the teacher teaches well Because the children's math is not good, when holding the parents' meeting, I asked other parents which math platform taught well

At the beginning, I asked my friend, whose children are very good at learning. I asked him which platform is better. He recommended some platforms to me, and then I chose them by myself When I saw the tiktok, the APE was the most advertised, and my first contact with the net was APE counseling, so I chose this platform.

The main consideration is that children can cope with the exam Does it really help her to achieve her goal

The extracurricular class I reported to him is mainly Chinese class. My children's Chinese is not good. I hope that they can learn Chinese better through the course

Before purchasing, I will pay attention to the practicality of the course content. It's better to talk less, focus on the key points, and pay attention to the summary teaching of key knowledge points What I'm thinking about is that when the children have a demand for this course, I'll consider whether to buy it or not

Buy online classes mainly to see if there is any part of the content that children want to improve

I usually buy some urgent online lessons for children to solve their learning problems.

Attending classes is also a waste of children's time. I will only choose to buy online courses that are very practical for children

I will have the goal to choose the curriculum to improve the child's ability in some aspects Girls' thinking ability is weaker than boys, so I want to exercise my child's thinking more to make mathematics better

I will pay for quality courses, which can meet the needs of children's learning content or exceed expectations

Hope that children can make obvious progress through learning

My children especially like the teacher' lessons. Learning effect is particularly good

In the platform course, my children are very good at mathematics and simple methods

I will report online courses for children's weaknesses. If it is a targeted course, I will choose this course.

I will consider the platform for the targeted explanation of regional examination questions.

Because the examination syllabus of each province is different, the depth is different, and the scope is different. I Will choose such an online learning platform for children.

I will choose a professional platform for my children and choose the main courses. The platform is very professional. It have arranged when my children will learn English and when they will learn mathematics during the holidays

Online class must have a management mode, such as building a group to punch in, which is not only conducive to two-way communication, but also promotes children to keep learning.

The reason for choosing this platform is that children can have a simulated test every month, and the simulated test will also be explained by video.

The question bank of this platform is very large, and each question in the question bank has a video explanation in addition to the text explanation.

The course is live broadcast, and you can look back after the live broadcast. Unlike some platforms that expire after one or two years, this platform does not expire.

Microblog has a question and answer system. If children have any questions about learning, they can leave a message under the teacher's microblog, and the teacher will reply.

The main reason for choosing this platform is that there are many comments on the teaching content under its courses, which are very real, and its popularity is also very high.

I mainly look at the evaluation of learning effect. If learning is effective, my children's learning may also be effective.

Look at the buyer's course evaluation, and read all the teacher's evaluation on the course website. The reason for choosing this online course is that the teacher is famous and has celebrity aura, which is easy to be accepted by parents, and they feel reliable. And only online class is suitable for my children. 
TABle 3: Continued.

\begin{tabular}{lc}
\hline Open coding & Original statement \\
\hline B63 public praise & $\begin{array}{r}\text { I'll search for these courses. Everyone tends to choose which platform I will choose for children, } \\
\text { just like taobao shopping, mainly depends on public praise. }\end{array}$ \\
B64 payment selection & $\begin{array}{r}\text { I will choose a professional platform for my children, because it is really well done, and the } \\
\text { results of the class are expected. In addition, I think that if there is a reward mechanism and } \\
\text { good service, it will attract children to continue learning. }\end{array}$ \\
B65 payment basis & $\begin{array}{r}\text { I will consider the platform information, teacher's recommendation, parents' recommendation, } \\
\text { online comments and so on, and finally choose the most suitable one for children. }\end{array}$ \\
\hline
\end{tabular}

TABLE 4: Spindle code (part).

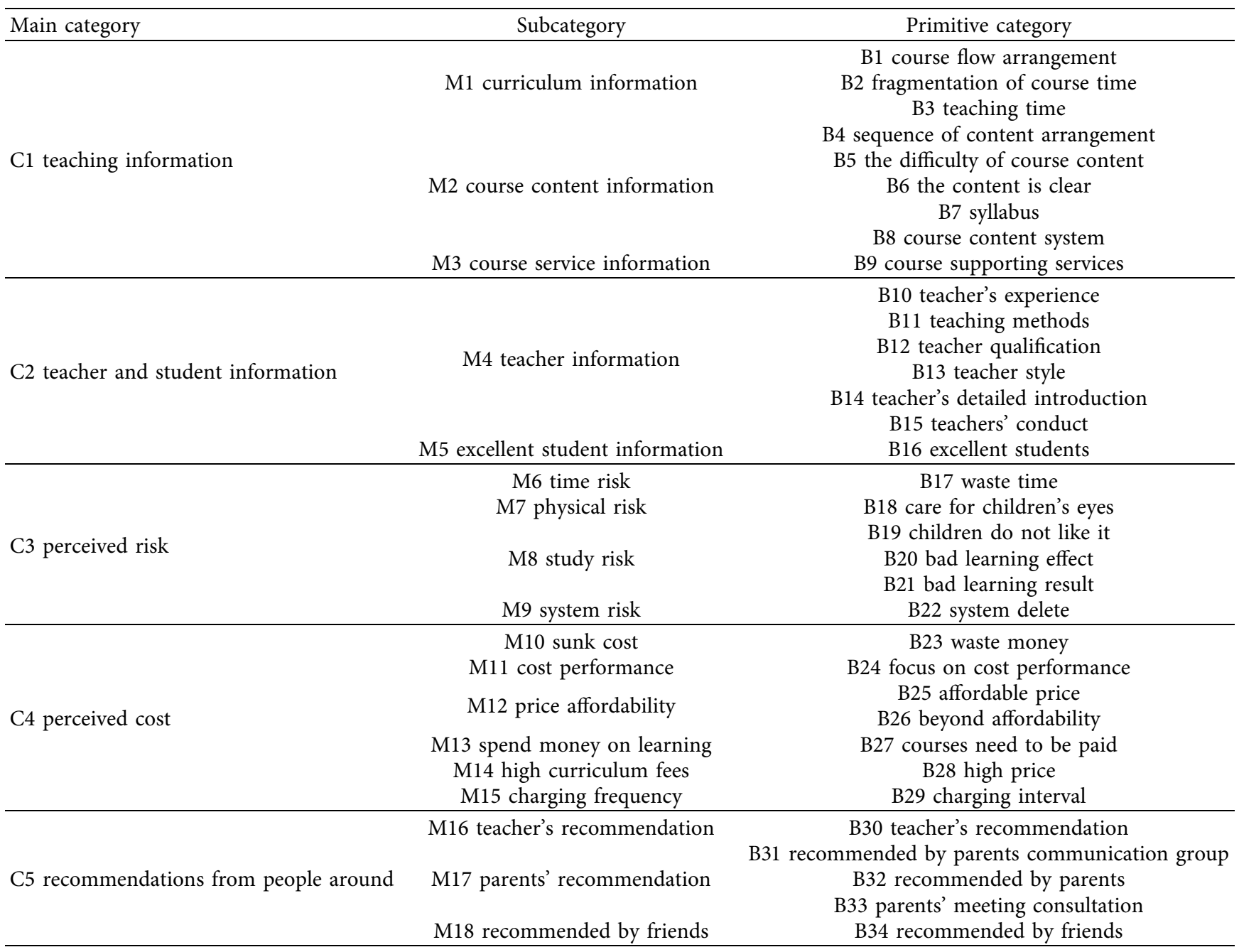

content perceived by middle school students' parents matches their children's needs. Since Fred proposed the TAM model [15], although with the continuous development of different scholars, perceived usefulness and perceived ease of use have been assumed to be factors affecting the use of technology [6]. Consumers will judge the consequences and behaviors after taking behaviors according to their perceived usefulness. This paper takes perceived usefulness as a part of perceived benefits and perceived usefulness as a antecedent variable of perceived value to explore the impact of perceived usefulness on perceived value and willingness to pay. Perceived usefulness has been widely used in information systems and technology research, and as an important indicator of forecasting technology adoption [16, 17]. Based on the above research results, this paper puts forward the hypothesis: 
Table 5: Spindle code.

\begin{tabular}{|c|c|c|}
\hline Main category & Subcategory & Primitive category \\
\hline C1 teaching information & $\begin{array}{l}\text { M2 course content information } \\
\text { M3 course service information }\end{array}$ & $\begin{array}{c}\text { B1 course flow arrangement } \\
\text { B2 fragmentation of course time } \\
\text { B3 teaching time } \\
\text { B4 sequence of content arrangement } \\
\text { B5 The difficulty of course content } \\
\text { B6 The content is clear } \\
\text { B7 syllabus } \\
\text { B8 course content system } \\
\text { B9 course supporting services }\end{array}$ \\
\hline C2 teacher and student information & $\begin{array}{c}\text { M4 teacher information } \\
\text { M5 excellent student information }\end{array}$ & $\begin{array}{c}\text { B10 teacher's experience } \\
\text { B11 teaching methods } \\
\text { B12 teacher qualification } \\
\text { B13 teacher style } \\
\text { B14 teacher's detailed introduction } \\
\text { B15 teachers' conduct } \\
\text { B16 excellent students }\end{array}$ \\
\hline C3 perceived risk & $\begin{array}{c}\text { M6 time risk } \\
\text { M7 physical risk }\end{array}$ & $\begin{array}{c}\text { B17 waste time } \\
\text { B18 care for children's eyes } \\
\text { B19 children do not like it } \\
\text { B20 bad learning effect } \\
\text { B21 bad learning result } \\
\text { B22 system delete }\end{array}$ \\
\hline C4 perceived cost & $\begin{array}{c}\text { M10 sunk cost } \\
\text { M11 cost performance } \\
\text { M12 price affordability } \\
\text { M13 spend money on learning } \\
\text { M14 high curriculum fees } \\
\text { M15 charging frequency }\end{array}$ & $\begin{array}{l}\text { B23 waste money } \\
\text { B24 focus on cost performance } \\
\text { B25 affordable price } \\
\text { B26 beyond affordability } \\
\text { B27 courses need to be paid } \\
\text { B28 high price } \\
\text { B29 charging interval }\end{array}$ \\
\hline C5 recommendations from people around & $\begin{array}{l}\text { M16 teacher's recommendation } \\
\text { M17 parents' recommendation } \\
\text { M18 recommended by friends }\end{array}$ & $\begin{array}{c}\text { B30 teacher's recommendation } \\
\text { B31 recommended by parents communication group } \\
\text { B32 recommended by parents } \\
\text { B33 parents' meeting consultation } \\
\text { B34 recommended by friends }\end{array}$ \\
\hline C6 external publicity & M19 media publicity & B35 network media publicity \\
\hline C7 help to improve learning & M20 improve learning outcomes & $\begin{array}{c}\text { B36 coping with exams } \\
\text { B37 achieve the goal } \\
\text { B38 improve the level of Chinese } \\
\text { B39 focus on teaching } \\
\text { B40 the needs of the curriculum } \\
\text { B41 the content meets the needs of children } \\
\text { B42 emergency learning } \\
\text { B43 course application }\end{array}$ \\
\hline C8 help to improve ability & M23 improve learning ability & $\begin{array}{c}\text { B44 improve children's ability } \\
\text { B45 improve mathematical thinking }\end{array}$ \\
\hline C9 perceived value & $\begin{array}{l}\text { M24 the learning effect is remarkable } \\
\text { M25 master key learning methods } \\
\text { M26 the course is highly targeted }\end{array}$ & $\begin{array}{c}\text { B46 beyond expectations } \\
\text { B47 obvious progress } \\
\text { B48 the effect is remarkable } \\
\text { B49 learn the key points } \\
\text { B50 targeted learning } \\
\text { B51 explanation of regional examination questions } \\
\text { B52 platform major and main courses } \\
\text { B53 the course arrangement is reasonable } \\
\text { B54 building a learning group } \\
\text { B55 mock examination } \\
\text { B56 intelligent question bank } \\
\text { B57 course playback does not expire } \\
\text { B58 microblog Q \& A }\end{array}$ \\
\hline
\end{tabular}


TABle 5: Continued.

\begin{tabular}{|c|c|c|}
\hline Main category & Subcategory & Primitive category \\
\hline \multirow{5}{*}{ C10 online comments } & M29 content review & B59 content review \\
\hline & M30 impact assessment & B60 impact assessment \\
\hline & & B61 teacher evaluation \\
\hline & M31 teacher evaluation & B62 celebrity effect \\
\hline & M32 word of mouth review & B63 public praise \\
\hline C11 willingness to pay & M33 course payment & $\begin{array}{l}\text { B64 payment options } \\
\text { B65 payment basis }\end{array}$ \\
\hline
\end{tabular}

TABLE 6: Selective coding.

\begin{tabular}{lc}
\hline Concept & Main category \\
\hline N1 course information & C1 teaching information \\
N2 perceived risk & C2 teacher and student information \\
N3 perceived cost & C3 perceived risk \\
N4 social influence & C4 perceived cost \\
N5 perceived usefulness & C5 recommendations from people around \\
N6 perceived value & C6 external publicity \\
N7 online comments & C7 help to improve learning \\
N8 willingness to pay & C8 help to improve ability \\
\hline
\end{tabular}

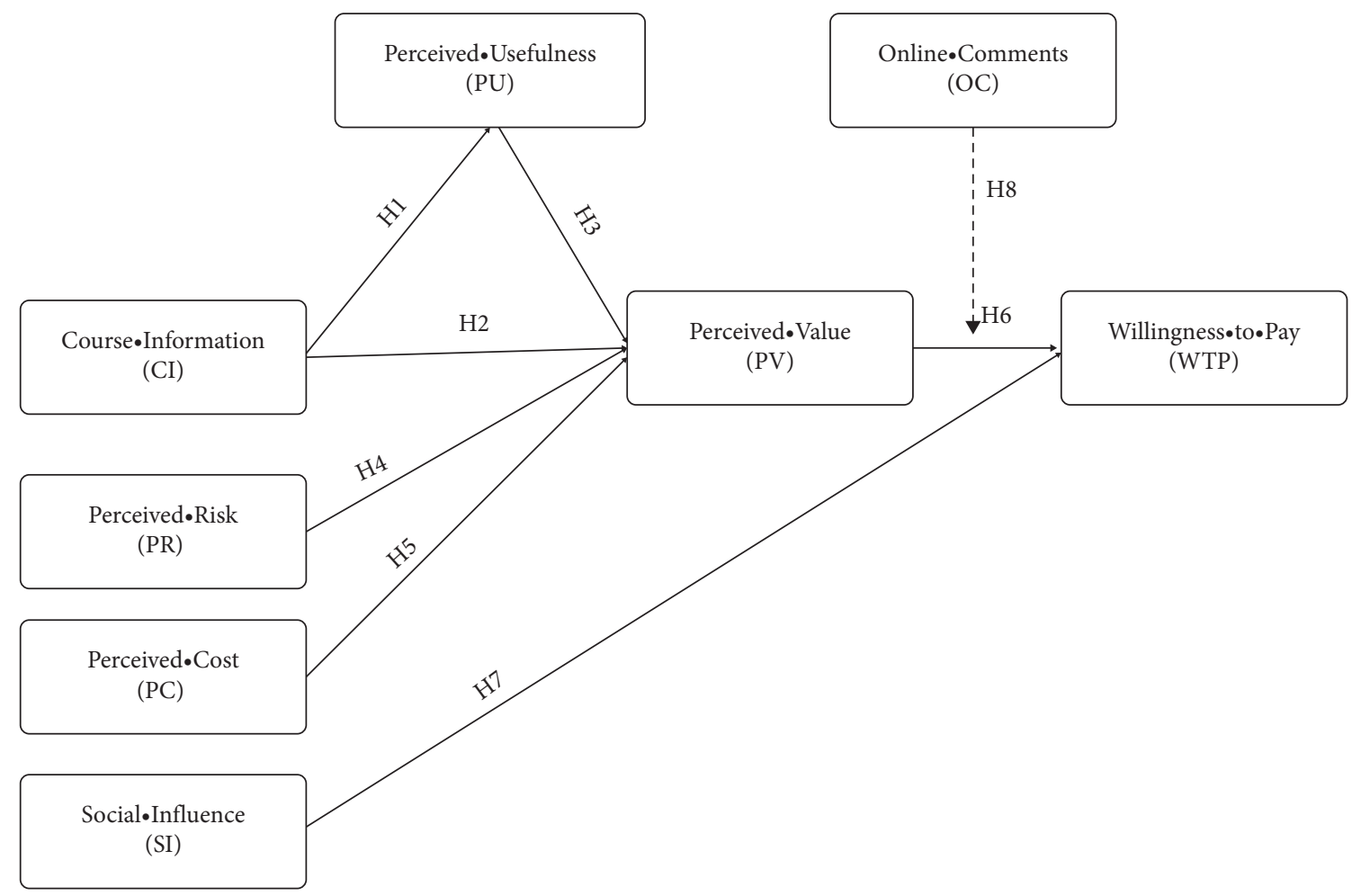

Figure 1: Model and hypothesis.

Hypothesis 3: perceived usefulness has a positive impact on perceived value of middle school students' parents in online learning platform.
3.3. Perceived Risk (PR). Hunter et al. divide perceived risk into two parts: risk importance and risk probability. In the context of e-commerce, the perceived risk of purchasing 
decisions originates from the buyer's perception of the importance of the potential negative consequences of purchasing wrong products and the probability of making wrong decisions [18]. Perceived risk reflects uncertainty, loss, and out of control over the purchase of products or services. This paper takes perceived risk as a part of perceived loss in perceived value and explores its impact on perceived value from the nonmonetary perspective of perceived loss. In general, perceived risk has a negative impact on the perceived value of products/services purchased by consumers. Under uncertain conditions, customers tend to avoid risks. Based on the above research results, this paper puts forward the hypothesis:

Hypothesis 4: perceived risk has a negative impact on perceived value of middle school students' parents in online learning platform.

3.4. Perceived Cost (PC). Perceived cost (perceived fee or perceived price) is the monetary transaction cost paid by consumers when purchasing products or services [19]. Kim and Gupta defined the perceived price as the perceived price level of the target price compared with the reference price of customers [20]. Generally, customers cannot accurately remember the actual price of the purchased goods. On the contrary, they will define the price of the purchased goods by their own unique coding method, or higher than or lower than the actual price. In this paper, perceived cost is regarded as a part of perceived loss in perceived value, and its influence on perceived value is explored from the monetary perspective of perceived loss. Online learning platform provides courses for students. Parents pay for courses. Parents' perceived cost of online learning platform courses affects their perceived value of courses. Based on existing research results, this paper puts forward assumptions:

Hypothesis 5: perceived cost has a negative impact on perceived value of middle school students' parents in online learning platform.

3.5. Perceived Value $(P V)$. Perceived value is defined as consumers' overall evaluation of the utility of a product or service, which is determined by consumers' perception of what they get and what they give [21]. The two dimensions of perceived benefit and perceived sacrifice are equally important for the evaluation of perceived value [22]. Perceived value can be increased by increasing perceived benefits and decreasing perceived payout, and the total perceived value can be obtained by comparing the net benefits of perceived benefits and perceived sacrifice [23]. This is a comprehensive process of perception trade-off. In the process of research, this paper measures the perceived value by considering the perceived gain and perceived sacrifice. Research shows that the perceived value of products or services in the Internet environment has a positive impact on the behavioral intention of using and purchasing $[24,25]$. The learning behavior of middle school students on the online learning platform is essentially that the online learning platform provides a learning environment and learning services for middle school students, so that middle school students can obtain the corresponding knowledge through the corresponding online products.

Hypothesis 6: perceived value of online learning platform has a positive impact on middle school students' parents' willingness to pay.

3.6. Social Influence (SI). Social influence represents the pressure of subjective norms, which is defined as "perception of group influence on an individual's decision" [1]. When individuals make decisions, they are often exposed to the opinions of others, especially influenced by family members, friends, colleagues, or celebrities. We call this group reference group (RG). Compared with the old users, new users have less cognition of products or services and no previous experience, so new users tend to rely on the evaluation and cognition of the reference group for judgment [26]. In the e-learning environment, the reference groups of students are mainly friends and classmates [27]. In the case that parents of middle school students generally pay more attention to their children's learning situation, parents are more cautious about their children's online learning platform selection and final payment. Based on the existing research results, this paper puts forward the following hypotheses.

Hypothesis 7: social influence has a positive impact on middle school students' parents' willingness to pay for online learning platform.

3.7. Online Comments (OC). Zhao et al. believed that online comments are online reviews conducted by consumers in the form of text [28]. In their research, Wang et al. defined eWOM as potential, realistic, or previous customer's positive or negative comments on corporate products or enterprises transmitted to others or institutions through the Internet [29]. The study by Parry and Kawakami defines virtual wordof-mouth as an online communication between consumers who have never met [24].

Online reviews can effectively reduce perceived risks and uncertainties of customers [30]. Consumers believe that both positive and negative online reviews are superior to information provided by product providers or service providers, and they will be regarded as important reference factors when making purchase and purchase decisions. Some studies have shown that online comments affect consumers' behavior [31, 32]. Consumers obtain more authentic reference information through online comments as the basis for decision-making, affecting payment behavior. With the development of online learning platform, relevant enterprises are also exploring how to use online comments to influence consumers' purchase decisions and adjust marketing strategies by evaluating the impact of online comments. Based on the above research, the paper puts forward the hypothesis: 
Hypothesis 8: online comments have a positive moderating effect on perceived value and middle school students' parents' willingness to pay in online learning platform.

3.8. Conceptual Model. When constructing the model of parents' willingness to pay on the online learning platform for middle school students, seven variables affecting the willingness to pay are extracted based on grounded theory, which are course information, perceived usefulness, perceived value, perceived risk, perceived cost, social influence, and online comments. In the process of model construction, by mining the relationship between categories and combing the relationship between variables in the literature, it is finally determined to form a payment willingness mechanism model based on perceived value theory. Based on the theory of perceived value, perceived value includes perceived benefits and perceived losses. Therefore, course information and perceived usefulness are regarded as variables affecting perceived benefits in perceived value. Perceived risk and perceived cost are divided into variables affecting perceived losses. External situational variables include social influence and online comments. Social influence focuses on the impact of group opinions closely related to buyers on their willingness to pay. Online comments focus on the impact of comments and opinions of strangers on products needed and buyers' willingness to pay. The external situational factors are more comprehensive by classifying groups that affect buyers' willingness to pay. Such variable classification and analysis form the theoretical model of this study. Figure 1 shows the model and assumptions.

\section{Empirical Study}

4.1. Questionnaire Design. After grounded theory and variable definition, this paper explores the specific relationship between variables through empirical research. The questionnaire mainly includes two parts: the basic information part and the paper structure research part. The former focuses on the gender, age, education level, and income level of the respondents, and the latter focuses on the attitude of the respondents to the dimensions related to the willingness to pay for online learning platforms. Since the measurement items in the structural part of the paper are initially English, in order to ensure semantic equivalence, the questionnaire follows the procedure of reverse translation. Two translation experts in the online education industry are invited to translate English items into Mandarin, and to retranslate ordinary topic items into English. The problem of translation inconsistency is solved. The five-point Likert scale was used for the related items in the structure of the paper, ranging from 1 "disagree" to 5 "agree." Combined with the specific semantic expression of online learning platform, four items of perceived value (PV) are adapted from Wang et al. [19]. The three items of the course information of perceived benefit in perceived value are adapted from Chiu et al. [33] and Zhou et al. [14], and the three items of perceived usefulness are adapted from Fred [15]. The three items of perceived risk and perceived cost in perceived value are adapted from Zhao et al. [28] and Wang et al. [19]. Three items of social influence in external situational factors and four items of online comments were adapted from Mehta et al. [1] and Zhao et al. [28]. The four items of dependent variable willingness to pay are adapted from Raghu et al. [34].

4.2. Data Collection and Analysis. The research subjects of this study were parents of middle school students who paid for online learning platform courses. Participants in the empirical phase were asked to answer all the items in the questionnaire according to their payment experience of online learning platform. This study adopts the sampling survey method, through the communication with the cooperative school, and finally decided to focus on three days (February 5, 2021 to February 7, 2021) for online sampling survey. A total of 900 questionnaires were distributed through the online survey platform (questionnaire star), and 792 questionnaires were recovered. Finally, 745 valid data samples were obtained for empirical analysis. The recovery rate and effective rate of the questionnaire were $88 \%$ and $94 \%$. The criteria for judging invalid questionnaires were as follows. (1) There were too many missing items in the questionnaire; (2) all the answers to the questions are the same; (3) the answers before and after the questions have obvious contradictory response.

In this paper, SPSS22 and AMOS24 are used to analyze the data of three parts. SPSS is mainly used for data coding, cleaning, and descriptive statistical analysis. Amos is mainly used to analyze the reliability, discriminant validity, and confirmatory factor analysis (CFA) of the measurement model, and to verify the hypotheses and regulatory effects of structural equation model through Amos.

\section{Results}

5.1. Demographic Profile. The demographic data of the sample are shown in Table 7 below. The ratio of male to female is approximately $1: 3$, with 191 males (25.6\%) and 554 females (74.4\%). It reflects that the education of Chinese parents to their children is mainly undertaken by their mothers. The educational level of parents of middle school students mainly concentrated in junior high school (49.5\%) and junior college/undergraduate (32.6\%), and the age group mainly concentrated in 36-40 years old (31.9\%) and 41-45 years old (34.2\%). More than half of the parents' monthly income level was less than 5000 yuan. Considering the proportion of sample size and items, the sample size of this study is sufficient [35]. Data show that economic income cannot directly reflect the impact of willingness to deal with fees.

5.2. Measurement Model. The confirmatory factor analysis (CFA) of the measurement model is carried out with 
TABLE 7: Demographic data.

\begin{tabular}{|c|c|c|c|c|}
\hline Population profile & Category & Frequency & Frequency & Cumulative percentage (\%) \\
\hline \multirow{2}{*}{ Gender } & Male & 191 & 25.6 & 25.6 \\
\hline & Female & 554 & 74.4 & 100.0 \\
\hline \multirow{4}{*}{ Education degree } & Master or above & 14 & 1.9 & 1.9 \\
\hline & Junior college/undergraduate & 243 & 32.6 & 34.5 \\
\hline & High school & 119 & 16.0 & 50.5 \\
\hline & Junior high school & 369 & 49.5 & 100.0 \\
\hline \multirow{5}{*}{ Age bracket } & $30-35$ & 52 & 7.0 & 7.0 \\
\hline & $36-40$ & 238 & 31.9 & 38.9 \\
\hline & $41-45$ & 255 & 34.2 & 73.2 \\
\hline & $46-50$ & 135 & 18.1 & 91.3 \\
\hline & Other & 65 & 8.7 & 100.0 \\
\hline \multirow{5}{*}{ Monthly income level } & Over 8000 & 63 & 8.5 & 8.5 \\
\hline & $6500-8000$ & 41 & 5.5 & 14.0 \\
\hline & $5000-6500$ & 88 & 11.8 & 25.8 \\
\hline & $3500-5000$ & 208 & 27.9 & 53.7 \\
\hline & $2000-3500$ & 345 & 46.3 & 100.0 \\
\hline
\end{tabular}

TABLE 8: Results of confirmatory factor analysis.

\begin{tabular}{|c|c|c|c|c|c|c|c|c|c|}
\hline \multirow[t]{2}{*}{ Dimension } & \multirow[t]{2}{*}{ Subject } & \multicolumn{4}{|c|}{$\begin{array}{c}\text { Parameter significance } \\
\text { estimation }\end{array}$} & \multirow{2}{*}{$\begin{array}{l}\text { Factor load } \\
\text { Std. }\end{array}$} & \multirow{2}{*}{$\begin{array}{c}\text { Subject reliability } \\
\text { SMC }\end{array}$} & \multirow{2}{*}{$\begin{array}{c}\text { Composite reliability } \\
\text { CR }\end{array}$} & \multirow{2}{*}{$\begin{array}{c}\text { Convergent validity } \\
\text { AVE }\end{array}$} \\
\hline & & Unstd. & S.E. & $t$ value & $p$ & & & & \\
\hline \multirow{3}{*}{ CI } & CI1 & 1.000 & & $\mathrm{NA}$ & & 0.835 & 0.697 & \multirow{3}{*}{0.926} & \multirow{3}{*}{0.807} \\
\hline & $\mathrm{CI} 2$ & 1.077 & 0.033 & 33.108 & $* * *$ & 0.935 & 0.874 & & \\
\hline & $\mathrm{CI} 3$ & 1.053 & 0.032 & 32.673 & $* * *$ & 0.922 & 0.850 & & \\
\hline \multirow{3}{*}{$\mathrm{PU}$} & PU1 & 1.000 & & NA & & 0.785 & 0.616 & \multirow{3}{*}{0.921} & \multirow{3}{*}{0.797} \\
\hline & PU2 & 1.208 & 0.041 & 29.742 & $* * *$ & 0.943 & 0.889 & & \\
\hline & PU3 & 1.210 & 0.041 & 29.718 & $* * *$ & 0.942 & 0.887 & & \\
\hline \multirow{4}{*}{ PV } & PV1 & 1.000 & & NA & & 0.745 & 0.555 & \multirow{4}{*}{0.890} & \multirow{4}{*}{0.670} \\
\hline & PV2 & 1.061 & 0.051 & 20.866 & $* * *$ & 0.771 & 0.594 & & \\
\hline & PV3 & 1.193 & 0.050 & 23.725 & $* * *$ & 0.877 & 0.769 & & \\
\hline & PV4 & 1.170 & 0.050 & 23.602 & $* * *$ & 0.872 & 0.760 & & \\
\hline \multirow{3}{*}{ PR } & PR1 & 1.000 & & NA & & 0.767 & 0.588 & \multirow{3}{*}{0.868} & \multirow{3}{*}{0.689} \\
\hline & PR2 & 1.217 & 0.053 & 23.091 & $* * *$ & 0.925 & 0.856 & & \\
\hline & PR3 & 1.028 & 0.047 & 22.076 & $* * *$ & 0.789 & 0.623 & & \\
\hline \multirow{3}{*}{ PC } & $\mathrm{PC} 1$ & 1.000 & & NA & & 0.838 & 0.702 & \multirow{3}{*}{0.782} & \multirow{3}{*}{0.548} \\
\hline & $\mathrm{PC} 2$ & 0.819 & 0.053 & 15.315 & $* * *$ & 0.734 & 0.539 & & \\
\hline & PC3 & 0.728 & 0.050 & 14.512 & $* * *$ & 0.635 & 0.403 & & \\
\hline \multirow{3}{*}{ SI } & SI1 & 1.000 & & $\mathrm{NA}$ & & 0.851 & 0.724 & \multirow{3}{*}{0.824} & \multirow{3}{*}{0.611} \\
\hline & SI2 & 0.876 & 0.046 & 18.961 & $* * *$ & 0.768 & 0.590 & & \\
\hline & $\mathrm{SI} 3$ & 0.830 & 0.045 & 18.347 & $* * *$ & 0.721 & 0.520 & & \\
\hline \multirow{4}{*}{ WTP } & WTP1 & 1.000 & & NA & & 0.777 & 0.604 & \multirow{4}{*}{0.909} & \multirow{4}{*}{0.715} \\
\hline & WTP2 & 1.065 & 0.045 & 23.906 & $* * *$ & 0.816 & 0.666 & & \\
\hline & WTP3 & 1.175 & 0.045 & 25.938 & $* * *$ & 0.873 & 0.762 & & \\
\hline & WTP4 & 1.177 & 0.043 & 27.069 & $* * *$ & 0.910 & 0.828 & & \\
\hline \multirow{4}{*}{ OC } & $\mathrm{OC} 1$ & 1.000 & & NA & & 0.663 & 0.440 & \multirow{4}{*}{0.803} & \\
\hline & OC2 & 1.185 & 0.072 & 16.395 & $* * *$ & 0.783 & 0.613 & & \\
\hline & OC3 & 1.159 & 0.071 & 16.372 & $* * *$ & 0.780 & 0.608 & & 0.507 \\
\hline & OC4 & 0.862 & 0.063 & 13.745 & $* * *$ & 0.607 & 0.368 & & \\
\hline
\end{tabular}

Note $1 . \mathrm{CI}=$ course information; $\mathrm{PV}=$ perceived value; $\mathrm{PU}=$ perceived usefulness; $\mathrm{PR}=$ perceived risk; $\mathrm{PC}=$ perceived cost; $\mathrm{WTP}=$ willingness to pay; $\mathrm{SI}=$ social influence; $\mathrm{OC}=$ online comments. Unstd. $=$ unstandardized factor loading; S.E. $=$ standard error; $t$ value $=$ critical ratios; $\mathrm{NA}=$ not available (regression coefficient is fixed to 1.0); Std. = standardized factor loading; SMC = squared multiple correlations; $\mathrm{CR}=$ composite reliability; $\mathrm{AVE}=$ average variance extracted. Note $2 .{ }^{* * *} p<0.001 ; N=745$. 
TABLE 9: Validity evaluation of discriminant validity.

\begin{tabular}{lccccccc}
\hline & AVE & CI & PV & PU & PR & PC & WTP \\
\hline CI & 0.807 & $\mathbf{0 . 8 9 8}$ & & & & & \\
PV & 0.670 & 0.66 & $\mathbf{0 . 8 1 9}$ & & & & \\
PU & 0.797 & 0.548 & 0.74 & $\mathbf{0 . 8 9 3}$ & & & \\
PR & 0.689 & 0.131 & 0.022 & 0.144 & $\mathbf{0 . 8 3 0}$ & & \\
PC & 0.548 & 0.158 & 0.016 & 0.112 & 0.658 & $\mathbf{0 . 7 4 0}$ & \\
WTP & 0.715 & 0.57 & 0.691 & 0.913 & 0.21 & 0.208 & $\mathbf{0 . 8 4 6}$ \\
SI & 0.611 & 0.641 & 0.784 & 0.807 & 0.201 & 0.223 & 0.865 \\
\hline
\end{tabular}

Notes. $\mathrm{CI}=$ course information; $\mathrm{PV}=$ perceived value; $\mathrm{PU}=$ perceived usefulness; $\mathrm{PR}=$ perceived risk; $\mathrm{PC}=$ perceived cost; $\mathrm{WTP}=$ willingness to pay; $\mathrm{SI}=$ social influence; Diagonals represent the square of AVE; Off-diagonal elements are the correlation.

TABle 10: Modified model fitting index.

\begin{tabular}{|c|c|c|c|c|c|c|c|c|c|c|c|}
\hline \multirow[t]{2}{*}{ Inspection quantity } & \multicolumn{4}{|c|}{ Absolute fitness index } & \multicolumn{5}{|c|}{ Value-added fitness index } & \multicolumn{2}{|c|}{$\begin{array}{l}\text { Parsimony } \\
\text { fitness index }\end{array}$} \\
\hline & $\chi^{2} / \mathrm{d} f$ & GFI & AGFI & RMSEA & NFI & RFI & IFI & TLI & CFI & PGFI & PNFI \\
\hline Good standard & $<3$ & $>0.9$ & $>0.9$ & $<0.08$ & $>0.9$ & $>0.9$ & $>0.9$ & $>0.9$ & $>0.9$ & $>0.5$ & $>0.5$ \\
\hline Model & 1.56 & 0.97 & 0.95 & 0.03 & 0.97 & 0.97 & 0.99 & 0.99 & 0.99 & 0.592 & 0.707 \\
\hline
\end{tabular}

Note. Goodness of fit of the model in 2000 bootstrap.

TABLE 11: Hypothesis test.

\begin{tabular}{|c|c|c|c|c|c|c|}
\hline Hypothesis & Standardized path coefficient & Nonstandard path coefficient & S.E. & $t$ value & $p$ & Result \\
\hline Hypothesis $1: \mathrm{CI} \longrightarrow \mathrm{PU}$ & 0.547 & 0.477 & 0.033 & 14.576 & $* * *$ & True \\
\hline Hypothesis $2: \mathrm{CI} \longrightarrow \mathrm{PV}$ & 0.359 & 0.305 & 0.028 & 10.724 & $* * *$ & True \\
\hline Hypothesis 3: PU $\longrightarrow \mathrm{PV}$ & 0.574 & 0.559 & 0.038 & 14.655 & $* * *$ & True \\
\hline Hypothesis 4: PR $\longrightarrow \mathrm{PV}$ & -0.060 & -0.054 & 0.023 & -2.303 & 0.021 & True \\
\hline Hypothesis 5: $\mathrm{PC} \longrightarrow \mathrm{PV}$ & -0.055 & -0.066 & 0.033 & -2.000 & 0.046 & True \\
\hline Hypothesis 6: PV $\longrightarrow$ WTP & 0.393 & 0.341 & 0.029 & 11.664 & $* * *$ & True \\
\hline Hypothesis 7: SI $\longrightarrow$ WTP & 0.719 & 0.631 & 0.040 & 15.969 & $* * *$ & True \\
\hline
\end{tabular}

Note. $\mathrm{CI}=$ course information; $\mathrm{PV}=$ perceived value; $\mathrm{PU}=$ perceived usefulness; $\mathrm{PR}=$ perceived risk; $\mathrm{PC}=$ perceived cost; $\mathrm{WTP}=$ willingness to pay; $\mathrm{SI}=$ social influence; Significant at ${ }^{* * *}: p<0.001$.

AMOS24 to test the relationship between the assumed observation variables and the assumed potential variables. In this study, CFA analysis was conducted on all dimensions -course information, perceived usefulness, perceived value, perceived risk, perceived cost, social influence, online comments, and willingness to pay. The standardized factor load of the eight dimensions was more than 0.6 and significant, and the item reliability was greater than 0.36 . The compositional reliability of the eight dimensions is above 0.7 , indicating good internal consistency; convergence validity (mean variance extraction) was greater than 0.5 , indicating that the convergence effect is good, as shown in Table 8. The results meet the criteria of Fornell and Larcker [36] and Hair et al. [37] that the factor load is greater than 0.5 , the component reliability is greater than 0.6 , and the convergence validity is greater than 0.5 . The discriminant validity is verified by comparing the correlation between the open root value of AVE and other dimensions. In this study, the discriminant validity of seven dimensions of independent variable and dependent variable is analyzed, and the results are shown in Table 9. The diagonal element in the matrix is the value of AVE root opening. Except that the value of AVE root sign perceived usefulness is slightly lower than the correlation coefficient between the user and the willingness to pay, and the free root number value of payment willingness is slightly lower than the correlation coefficient between it and social influence (the difference between the values is small), the value of AVE root opening in all dimensions is higher than the correlation between them and the relevant dimensions. Since the AVE method is a strict method to determine the difference validity, the result of the difference validity is acceptable in general.

5.3. Structural Model. The absolute fitness index, valueadded fitness index, and parsimony fitness index are used to measure the model. The measurement of absolute fitness index includes $\chi^{2} / \mathrm{d} f$, GFI, AGFI, and RMSEA. The valueadded fitness index includes NFI, RFI, IFI, TLI, and CFI. The measurement of parsimony fitness index includes PGFI and PNFI. In SEM analysis, it is basically impossible for the data to conform to the multivariate normal distribution [38], but nonmultivariate normality is easy to cause the expansion of chi square. Therefore, this paper uses Bollen Stine bootstrap procedure to adjust the model fitting and parameter estimation to adapt to the lack of multivariate normality 


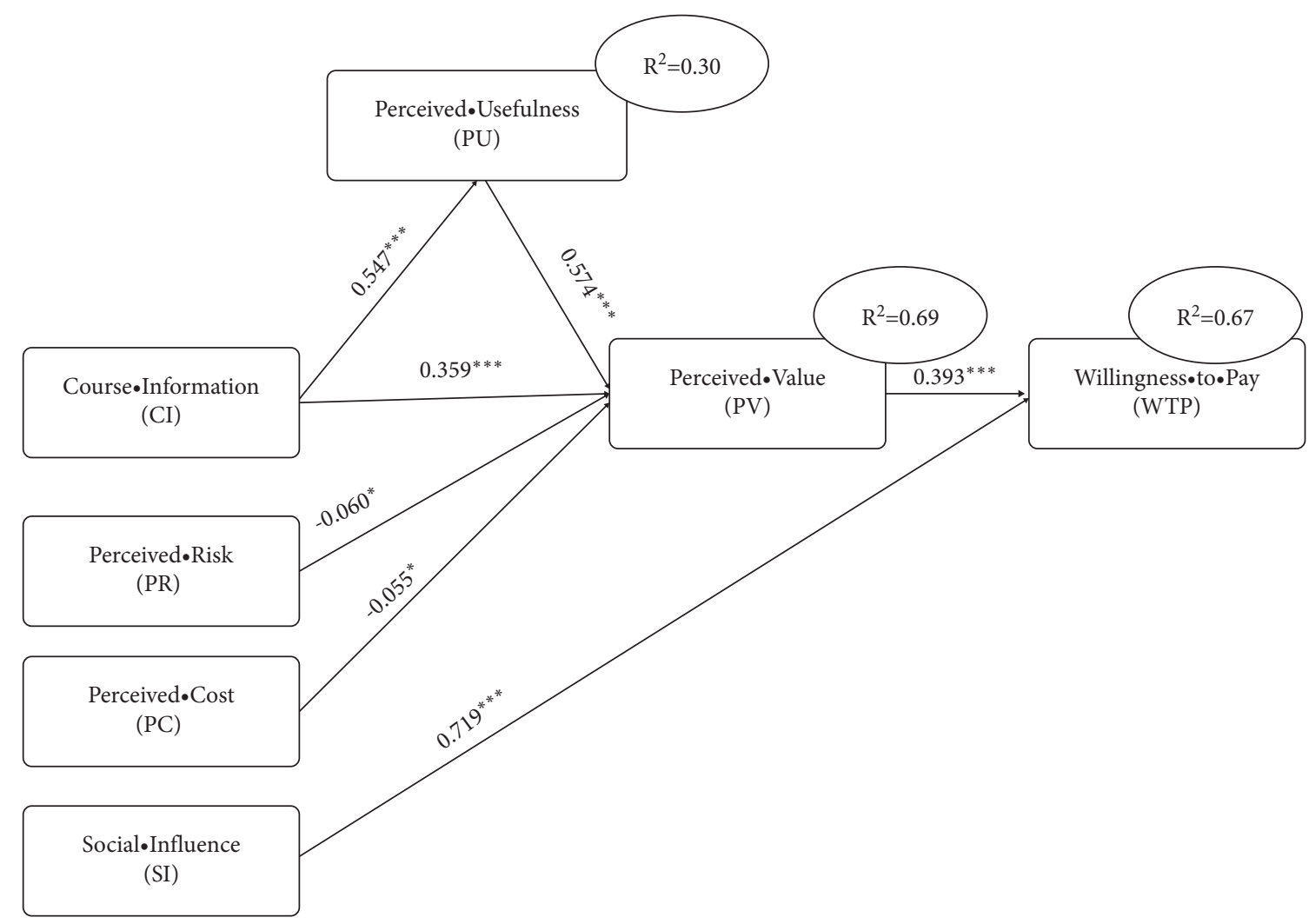

Figure 2: Hypothesis test results. Notes: ${ }^{*} p<0.05 ;{ }^{* * *} p<0.001$.

TABLE 12: Moderating effect of online reviews.

\begin{tabular}{lcccc}
\hline Path & Estimate & S.E. & C.R. & \\
\hline PV $\longrightarrow$ WTP & -0.044 & 0.054 & -0.811 & 0.417 \\
OC $\longrightarrow$ WTP & 0.794 & 0.061 & 12.926 & ${ }^{* * *}$ \\
PXO $\longrightarrow$ WTP & 0.028 & 0.006 & 4.992 & $* * *$ \\
\hline
\end{tabular}

$[39,40]$. The revised results are shown in Table 10 . The absolute fitness index, value-added fitness index, and parsimony fitness index are basically excellent.

As shown in Table 11 and Figure 2, the course information has a significant positive effect on perceived usefulness $\quad(\mathrm{CI} \longrightarrow \mathrm{PU}: \quad \beta=0.547, \quad t=14.576, \quad p<0.001)$; hypothesis 1 is true. The course information positively affected the perceived value $(\mathrm{CI} \longrightarrow \mathrm{PV}: \beta=0.359, t=10.724$, $p<0.001$ ), and hypothesis 2 was established. The perceived usefulness positively affected perceived value $(\mathrm{PU} \longrightarrow \mathrm{PV}$ : $\beta=0.574, \quad t=14.655, \quad p<0.001)$, and hypothesis 3 was established. Hypotheses 1-3 show that perceived usefulness and course information as perceived benefits positively affect perceived value. The perceived risk significantly negatively affected perceived value $(\mathrm{PR} \longrightarrow \mathrm{PV}: \beta=-0.060, t=-2.303$, $p=0.021<0.05$ ); hypothesis 4 was established. The perceived cost significantly negatively affected perceived value $(\mathrm{PC} \longrightarrow \mathrm{PV}: \beta=-0.055, t=-2.000, p=0.046<0.05)$; hypothesis 5 was established. Hypotheses 4-5 show that perceived risk and perceived cost have negative impact on perceived value as perceived losses. Perceived value positively affected willingness to pay (PV $\longrightarrow$ WTP: $\beta=0.393$, $t=11.664, p<0.001)$; hypothesis 6 was established. Social influence had a positive effect on willingness to pay (SI $\longrightarrow$ WTP: $\beta=0.719, t=15.969, p<0.001)$. The results of structural equation model analysis show that perceived usefulness explains 30\% variance, perceived value explains $69 \%$ variance, willingness to pay explains $67 \%$ variance, and the interpretation degree reaches the acceptable level of medium or above.

5.4. Adjustment Test. In general, it is difficult to use potential variables when analyzing interaction by structural equation. Firstly, nonlinear constraints must be applied to fixed factor coefficients and error variance to identify the effects of interaction. Secondly, it is difficult to confirm that the indicators of interaction items have normal distribution even if each variable that constitutes the interaction item has it. In order to solve the above problems and explore the moderating effect between perceived value and willingness to pay by online comments, this paper adopts two-step approach proposed by Ping [41] through amos24, which does not require nonlinear constraints. As shown in Table 12 and 


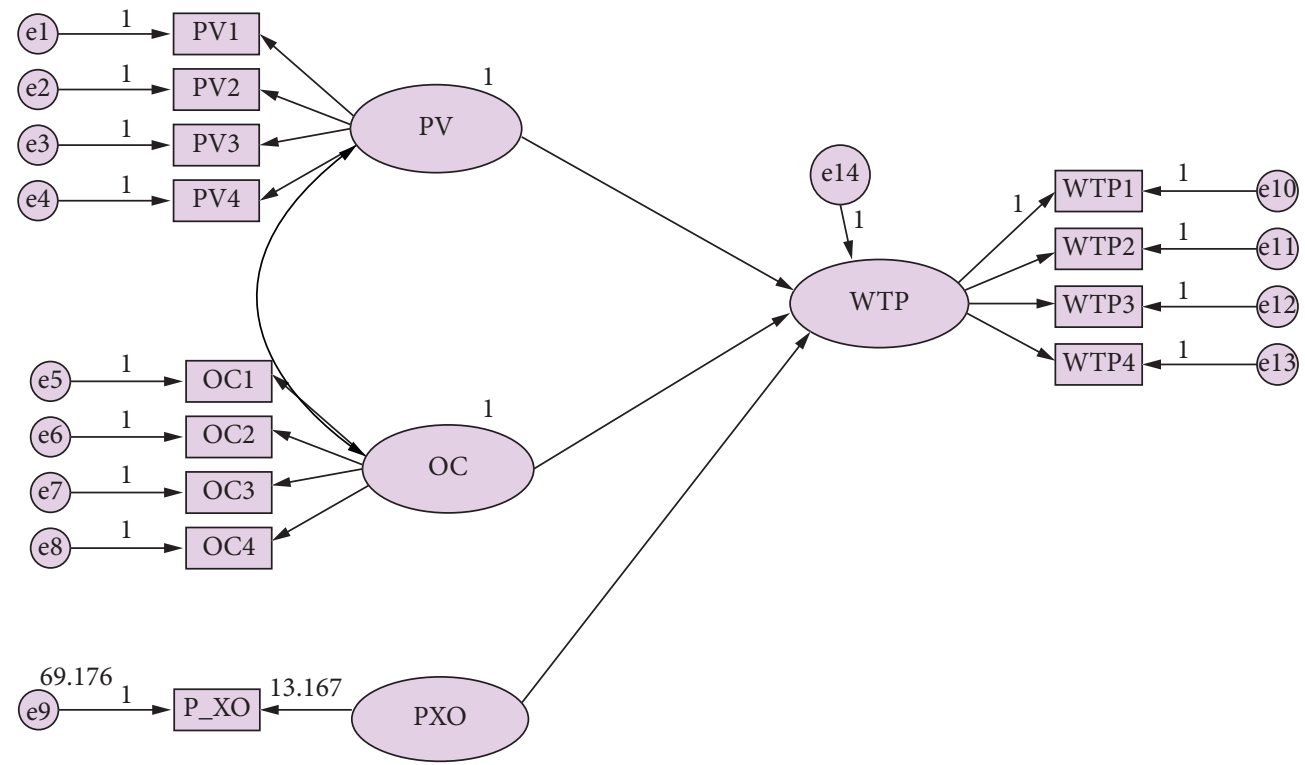

FIgURE 3: Moderating model of online reviews.

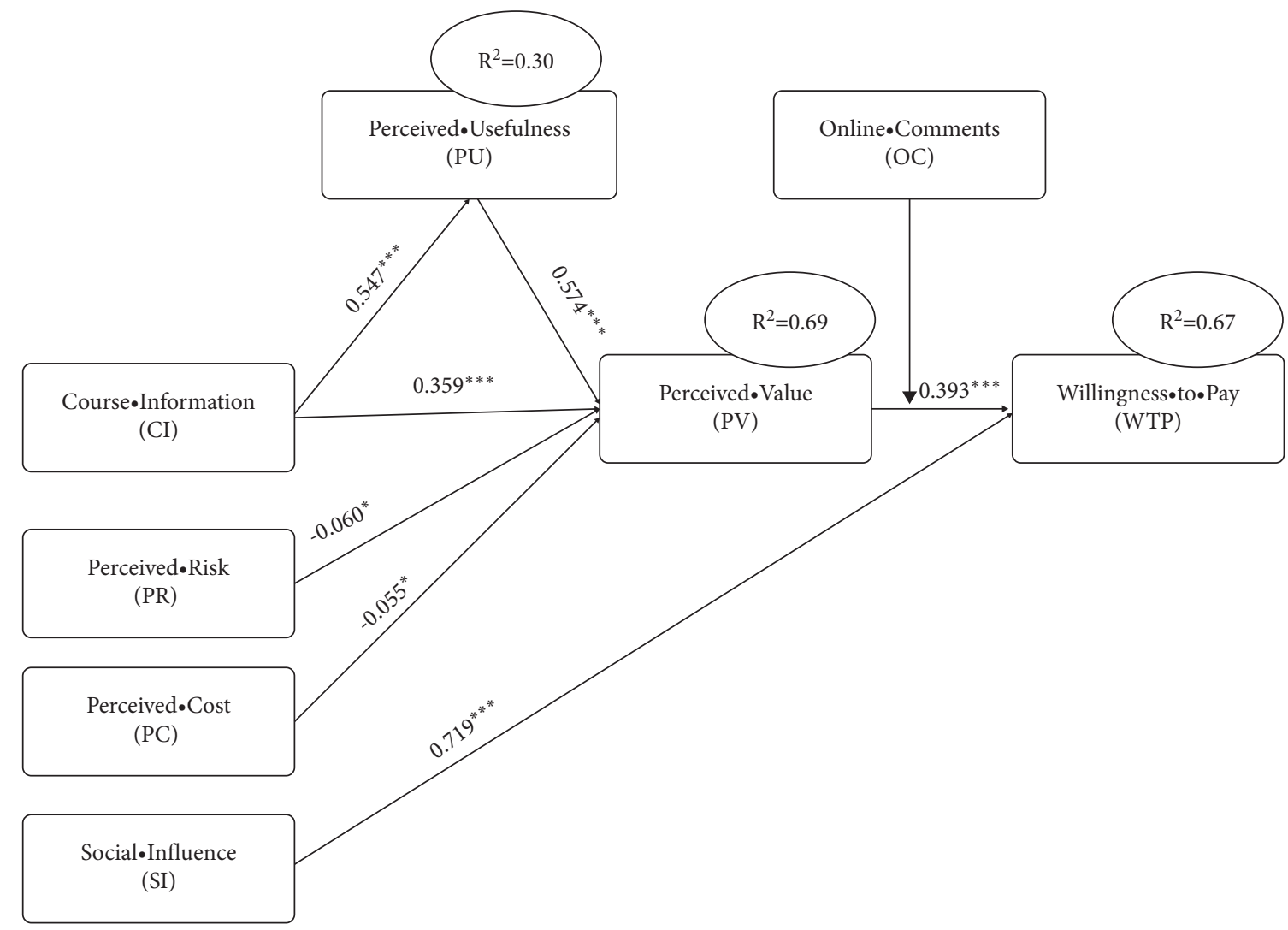

FIgURE 4: Final test results. Notes: ${ }^{*} p<0.05 ;{ }^{* * *} p<0.001$.

Figure 3, the interaction item PXO of perceived value and online comments has a positive and significant impact on the willingness to pay. Assuming that 8 is established, it is clear that online comments positively regulate the relationship between perceived value and willingness to pay.

The final test results of empirical research are shown in Figure 4 .

\section{Conclusion}

This paper judges the influence of users' perceived value and external situational factors on their willingness to pay. The proposed model comprehensively analyzes the willingness of middle school students' parents to pay for online learning platform from the personal subjective feelings (perceived value) 
and external situational factors (social influence and online comments of the pay group). At the same time, all the assumptions in this paper are verified. Course information directly affects perceived value and indirectly affects perceived value through perceived usefulness. Perceived risk and perceived cost negatively affect perceived value. Perceived value and social influence positively affect willingness to pay, and online comment positively moderates the relationship between perceived value and willingness to pay. Among the four dimensions that affect perceived value, perceived usefulness and course information positively affect perceived value, and the degree of positive influence of perceived usefulness is greater than that of course information. Perceived cost and perceived risk negatively affect perceived value, and perceived risk negatively affects more than perceived cost. Thus, the willingness to pay for online learning platforms is mainly determined by users' perceived value and external situational factors.

This study has made three important contributions to the theoretical development of willingness to pay. First of all, this paper combines the theory of perceived value and external situational factors to expand the model that explains the willingness to pay of middle school students' parents in online learning platforms, which is rarely discussed in the existing literature. Second, the results show that, compared with the parents' subjective feelings of online learning platform, external situational factors (social influence) have a stronger impact on the willingness to pay of middle school students' parents. Third, empirical analysis shows that online comments positively moderate the relationship between perceived value and willingness to pay, which fills the knowledge gap of the moderating effect of online comments on willingness to pay in previous studies.

\section{Data Availability}

Data sharing is not applicable to this article as no new data were created or analyzed in this study.

\section{Additional Points}

Limitations and Future Research. Limitations of research: previous studies have considered users and customers as a role. The online learning of middle school students has a special situation that users use and customers pay. Therefore, this study only considers the subjective and social factors of customers (parents) willingness to pay and does not consider the impact of use on their willingness to pay. This is not only an innovative attempt, but also may have limitations. Future research: since middle school students' online learning has the situation of customer-user separation, the future research should be based on this study to identify the impact of user use factors on customer willingness to pay, in order to study the mechanism of middle school students' online learning willingness to pay in the context of customer-user separation.

\section{Conflicts of Interest}

The authors declare that they have no conflicts of interest.

\section{Acknowledgments}

This work was supported by Undergraduate Teaching Reform Project of Guangxi Higher Education (2019JGA332).

\section{References}

[1] A. Mehta, N. P. Morris, B. Swinnerton, and M. Homer, "The influence of values on E-learning adoption," Computers \& Education, vol. 141, Article ID 103617, 2019.

[2] N. Luo, M. Zhang, and D. Qi, "Effects of different interactions on students' sense of community in E-learning environment," Computers \& Education, vol. 115, pp. 153-160, 2017.

[3] J.-C. Hong, K.-H. Tai, M.-Y. Hwang, Y.-C. Kuo, and J.-S. Chen, "Internet cognitive failure relevant to users' satisfaction with content and interface design to reflect continuance intention to use a government E-learning system," Computers in Human Behavior, vol. 66, pp. 353-362, 2017.

[4] H.-P. Shih, "Using a cognition-motivation-control view to assess the adoption intention for web-based learning," Computers \& Education, vol. 50, pp. 327-337, 2008.

[5] Ø. Sørebø, H. Halvari, V. F. Gulli, and R. Kristiansen, "The role of self-determination theory in explaining teachers' motivation to continue to use E-learning technology," Computers \& Education, vol. 53, pp. 1177-1187, 2009.

[6] M. Cheng and A. H. K. Yuen, "Student continuance of learning management system use: a longitudinal exploration," Computers \& Education, vol. 120, pp. 241-253, 2018.

[7] H. Motaghian, A. Hassanzadeh, and D. K. Moghadam, "Factors affecting university instructors' adoption of webbased learning systems: case study of Iran," Computers \& Education, vol. 61, pp. 158-167, 2013.

[8] H. M. Dai, T. Teo, N. A. Rappa, and F. Huang, "Explaining Chinese university students' continuance learning intention in the MOOC setting: a modified expectation confirmation model perspective," Computers \& Education, vol. 150, Article ID 103850, 2020.

[9] K. M. Alraimi, H. Zo, and A. P. Ciganek, "Understanding the MOOCs continuance: the role of openness and reputation," Computers \& Education, vol. 80, pp. 28-38, 2015.

[10] Z. Shao, "Examining the impact mechanism of social psychological motivations on individuals' continuance intention of MOOCs: the moderating effect of gender," Internet Research, vol. 28, no. 1, pp. 232-250, 2018.

[11] Y. J. Joo, H.-J. So, and N. H. Kim, "Examination of relationships among students' self-determination, technology acceptance, satisfaction, and continuance intention to use K-MOOCs," Computers \& Education, vol. 122, pp. 260-272, 2018.

[12] K. Charmaz, Constructing Grounded Theory: A Practical Guide through Qualitative Analysis, SAGE, Thousand Oaks, CA, USA, 2006.

[13] D.-H. Park, J. Lee, and I. Han, "The effect of on-line consumer reviews on consumer purchasing intention: the moderating role of involvement," International Journal of Electronic Commerce, vol. 11, no. 4, pp. 125-148, 2007.

[14] X. Zhou, Q. Song, Y.-y. Li, H. Tan, and H. Zhou, "Examining the influence of online retailers' micro-blogs on consumers' purchase intention," Internet Research, vol. 27, no. 4, pp. 819-838, 2017.

[15] D. Fred, "Perceived usefulness, perceived ease of use, and user acceptance of information technology," MIS Quarterly, vol. 13, no. 3, pp. 319-340, 1989. 
[16] K.-B. Ooi, J.-J. Hew, and V.-H. Lee, "Could the mobile and social perspectives of mobile social learning platforms motivate learners to learn continuously?" Computers \& Education, vol. 120, pp. 127-145, 2018.

[17] C.-T. Chang, J. Hajiyev, and C.-R. Su, "Examining the students' behavioral intention to use e-learning in Azerbaijan? The general extended technology acceptance model for E-learning approach," Computers \& Education, vol. 111, pp. 128-143, 2017.

[18] L. M. Hunter, C. J. Kasouf, K. G. Celuch, and K. A. Curry, “A classification of business-to-business buying decisions: risk importance and probability as a framework for e-business benefits," Industrial Marketing Management, vol. 33, no. 2, pp. 145-154, 2004.

[19] Y.-Y. Wang, H.-H. Lin, Y.-S. Wang, Y.-W. Shih, and S.-T. Wang, "What drives users' intentions to purchase a GPS navigation app," Internet Research, vol. 28, no. 1, pp. 251-274, 2018.

[20] H.-W. Kim and S. Gupta, "A comparison of purchase decision calculus between potential and repeat customers of an online store," Decision Support Systems, vol. 47, no. 4, pp. 477-487, 2009.

[21] K.-L. Hsiao and C.-C. Chen, "What drives in-app purchase intention for mobile games? An examination of perceived values and loyalty," Electronic Commerce Research and Applications, vol. 16, pp. 18-29, 2016.

[22] Y. Kim, Y. Park, and J. Choi, "A study on the adoption of IoT smart home service: using value-based adoption model," Total Quality Management \& Business Excellence, vol. 28, no. 9-10, pp. 1149-1165, 2017.

[23] N. Chung and C. Koo, "The use of social media in travel information search," Telematics and Informatics, vol. 32, no. 2, pp. 215-229, 2015.

[24] M. E. Parry and T. Kawakami, "Virtual word of mouth and willingness to pay for consumer electronic innovations," Journal of Product Innovation Management, vol. 32, no. 2, pp. 192-200, 2015.

[25] J.-C. Hong, P.-H. Lin, and P.-C. Hsieh, "The effect of consumer innovativeness on perceived value and continuance intention to use smartwatch," Computers in Human Behavior, vol. 67, pp. 264-272, 2017.

[26] E. Huang, "Online experiences and virtual goods purchase intention," Internet Research, vol. 22, no. 3, pp. 252-274, 2012.

[27] C. M. K. Cheung, M. K. O. Lee, and Z. W. Y. Lee, "Understanding the continuance intention of knowledge sharing in online communities of practice through the post-knowledgesharing evaluation processes," Journal of the American Society for Information Science and Technology, vol. 64, no. 7, pp. 1357-1374, 2013.

[28] X. Zhao, S. Deng, and Y. Zhou, "The impact of reference effects on online purchase intention of agricultural products," Internet Research, vol. 27, no. 2, pp. 233-255, 2017.

[29] J.-J. Wang, L.-Y. Wang, and M.-M. Wang, "Understanding the effects of eWOM social ties on purchase intentions: a moderated mediation investigation," Electronic Commerce Research and Applications, vol. 28, pp. 54-62, 2018.

[30] M. M. Al-Debei, M. N. Akroush, and M. I. Ashouri, "Consumer attitudes towards online shopping," Internet Research, vol. 25, no. 5, pp. 707-733, 2015.

[31] I. Erkan and C. Evans, "The influence of eWOM in social media on consumers' purchase intentions: an extended approach to information adoption," Computers in Human Behavior, vol. 61, pp. 47-55, 2016.
[32] Y.-w. Fan and Y.-f. Miao, "Effect of electronic word-of-mouth on consumer purchase intention: the perspective of gender differences," International Journal of Electronic Business Management, vol. 14, no. 1, pp. 93-107, 2012.

[33] C.-M. Chiu, E. T. G. Wang, Y.-H. Fang, and H.-Y. Huang, "Understanding customers' repeat purchase intentions in B2C e-commerce: the roles of utilitarian value, hedonic value and perceived risk," Information Systems Journal, vol. 24, no. 1, pp. 85-114, 2014.

[34] T. S. Raghu, R. Sinha, A. Vinze, and O. Burton, "Willingness to pay in an open source software environment," Information Systems Research, vol. 20, no. 2, pp. 218-236, 2009.

[35] M. Wu, The Statistical Analysis of the Questionnaire: The Operation and Application of SPSS (Chinese Version), Chongqing University Press, Chongqing, China, 2010.

[36] C. Fornell and D. F. Larcker, "Evaluating structural equation models with unobservable variables and measurement error," Journal of Marketing Research, vol. 18, no. 1, pp. 39-50, 1981.

[37] J. F. Hair, W. C. Black, B. J. Babin, and R. E. Anderson, Multivariate Data Analysis, Prentice Hall, Englewood Cliffs, NJ, USA, 7th edition, 2009.

[38] M. J. Fisher and J. King, “The self-directed learning readiness scale for nursing education revisited: a confirmatory factor analysis," Nurse Education Today, vol. 30, no. 1, pp. 44-48, 2010.

[39] K. A. Bollen and R. A. Stine, "Bootstrapping goodness-of-fit measures in structural equation models," Sociological Methods \& Research, vol. 21, no. 2, pp. 205-229, 1992.

[40] C. K. Enders, "An SAS macro for implementing the modified bollen-stine bootstrap for missing data: implementing the bootstrap using existing structural equation modeling software," Structural Equation Modeling: A Multidisciplinary Journal, vol. 12, no. 4, pp. 620-641, 2005.

[41] R. A. Ping, "A parsimonious estimating technique for interaction and quadratic latent variables," Journal of Marketing Research, vol. 32, pp. 336-347, 1995. 